\title{
Peran Majelis Taklim dalam Meningkatkan Religiusitas Masyarakat Melalui Kajian Kitab Rutinan di Desa Suci Kecamatan Panti Kabupaten Jember
}

\author{
Siti Humairoh \\ Pascasarjana Universitas Islam Negeri Sunan Kalijaga Yogyakarta. \\ zulzahumairoh@gmail.com
}

\begin{abstract}
The Taklim assembly is a forum for the community in order to gain knowledge about Islam, which is more open and usually carried out routinely. Therefore, the delivery of da'wah must also be adjusted to the local conditions of the community, the aim of which is to be easily understood and accepted by the community itself. This research will describe the role of the taklim assembly in increasing the religiosity of the community, how enthusiastic the community is in the taklim assembly, and what books are used as references in delivering their da'wah. This research is categorized in the type of qualitative-descriptive research with the methods of observation, interviews, and documentation, which in the future is expected to obtain more comprehensive data. The results of this study indicate that: 1) the taklim assembly, especially in the Suci-Panti Village, plays an important role for the community itself as in terms of religiosity which is basically reflected in the practice of aqidah, sharia, and morals (faith, Islam, and ihsan). In the taklim assembly which is held every Monday night Tuesday, it gets a very good response from the community, even the community is very enthusiastic when the study takes place, besides that in the assembly a discussion session is held. 2). The books that are used as references in the assembly consist of; aqidatul awam, mabadi'ul fiqhiyah, and lubabul hadith, which are discussed in depth.
\end{abstract}

Keywords: Taklim Assembly, Religiosity, Da’wah.

\begin{abstract}
Abstrak
Majelis Taklim merupakan suatu wadah bagi masyarakat dalam rangka untuk memperoleh ilmu tentang keislaman, yang sifatnya lebih terbuka dan biasanya dilakukan secara rutinan. Oleh karena itu, dalam penyampaian dakwahnya juga harus disesuaikan dengan kondisi lokal masyarakat, yang tujuannya agar mudah dipahami dan diterima oleh masyarakat itu sendiri. Dalam riset ini akan mendeskripsikan tentang bagaimana peran majelis taklim dalam meningkatkan religiusitas masyarakat, bagaimana antusiasisme masyarakat dalam majelis taklim, dan kitab-kitab apa saja yang dijadikan rujukan dalam penyampain dakwahnya. Riset ini dikategorikan dalam jenis penelitian kualitatif-deskriptif dengan metode observasi, wawancara, dan dokumentasi, yang pada nantinya diharapkan memperoleh data-data yang lebih komprehensif. Adapun hasil penelitian ini menunjukkan bahwa: 1) majelis taklim khususnya di Desa Suci- Panti sangat berperan penting bagi masyarakat itu sendiri seperti dari segi religiusitas nya yang pada dasarnya tercermin dalam pengamalan aqidah, syariah, dan
\end{abstract}


akhlak ( iman, islam, dan ihsan). Dalam majelis taklim yang diselenggarakan setiap senin malam selasa ini mendapat respon yang sangat baik dari masyarakat bahkan masyarakat sangat antusias ketika kajian berlangsung, selain itu dalam majelis tersebut diadakan sesi diskusi. 2). Kitab yang dijadikan rujukan dalam majelis tersebut yaitu terdiri dari; aqidatul awam, mabadi'ul fiqhiyah, dan lubabul hadits, yang dikupas secara mendalam.

Kata Kunci: Majelis Taklim, Religiusitas , Dakwah.

\section{Pendahuluan}

Islam merupakan agama misionaris dengan klaim universal, meliputi setiap aspek keberadaan manusia. Islam juga politik agama, mengajarkan bahwa ruang publik dan privat harus dipandu oleh kehendak Allah, seperti yang diwahyukan dalam Al-Qur'an dan dicontohkan dalam sunnah (perkataan dan tradisi Nabi Muhammad) kehidupan, yang dianggap normatif). Dalam Islam kita bertemu dengan sistem iman yang komprehensif yang membutuhkan penyerahan penuh oleh manusia kepada Allah. Umat Islam berkewajiban menyeru seluruh umat manusia untuk tunduk dan mengakui perintah Allah secara kaffah atas seluruh dunia. Mereka percaya bahwa manusia hanya menemukan jalan lurus (Allah) melalui Islam. Islam bukan hanya sekedar keyakinan, mementingkan aspek spiritual kehidupan, dan bukan hanya agama, akan tetapi konten untuk memainkan peran dalam sebuah masyarakat. Seperti halnya kegiatan berdakwah sebagaimana yang dicontohkan oleh Nabi Muhammad, bahwa sebagai seorang umat Muslim kita harus saling mengingatkan menyeru dalam hal kebajikan, menncegah terhadap hal-hal yang munkar yang tentunya dilakukan dengan cara yang baik. ${ }^{1}$

Misi kegiatan dakwah adalah suatu kegiatan atau proses yang dilakukan oleh suatu kesadaran dan berencana untuk mengajak manusia ke jalan Allah, untuk memperbaiki situasi menjadi lebih baik (dakwah adalah promosi dan pengembangan) dalam rangka mencapai tujuan tertentu, yaitu untuk hidup bahagia di dunia akhirat. Dengan demikian beberapa definisi dan terminologi dakwah yang baik menurut arti etimologis, semua menunjuk ke kegiatan yang bertujuan positif pada manusia. Perubahan positif diwujudkan dengan peningkatan keimanan. jika definisi dakwah dikaitkan dengan beberapa fenomena dakwah, maka dapat dinyatakan bahwa dakwah adalah proses peningkatan iman dalam diri manusia menurut syariat Islam bahwa "proses" menunjukkan aktivitas yang terus menerus, terus menerus dan bertahap. Seperti peningkatan kualitas perubahan positif: dari buruk menjadi baik, atau dari baik menjadi lebih baik. ${ }^{2}$ Ketika digunakan dalam hubungannya dengan Islam, itu

1 Albrecht Hauser, "Da'wah: Islamic Mission and Its Current Implications," International Bulletin of Missionary Research 36 No.4, no. October (2012): 189-94.

${ }^{2}$ Mubasyaroh, "Develop Quality People Through Da'Wah in the Face of the Asean Economic Community (Aec)," Addin 10, no. 2 (2016): 449, https://doi.org/10.21043/addin.v10i2.1785. 
dipahami berarti mengajak ke jalan kepasrahan dan penyerahan diri kepada Allah. Oleh karena itu, kemampuan seorang da'i sangat berpengaruh dalam penyampaian dakwahnya, da'i merupakan orang yang mengajak masyarakat untuk memahami Islam melalui dialog. Banyak umat Islam yang berdakwah menurut cara yang mereka sukai, namun hasilnya akan berbeda jika da'i menggunakan pemikiran kreatif. Karena Dakwah tidak hanya mengajak nonMuslim masuk Islam dan juga memahami umat Islam untuk realisasi akurat Islam dan praktiknya: lebih baik menerapkannya dengan pengetahuan yang benar, kebaikan dan keterampilan khusus. Merupakan amalan yang mulia dan wajib bagi setiap muslim yang mengucapkan syahadat. Pendekatan logis efektif dalam kegiatan dakwah karena dapat meyakinkan khalayak secara rasional dan wajar jika diperlukan. Ketika da'i menjelaskan tentang keberadaan Allah dan Tauhid, orang yang didekati mungkin bertanya-tanya untuk menunjukkan bukti keberadaan Allah SWT. Kemudian da'i dapat memberikan jawaban yang logis sambil membandingkan dengan sesuatu yang tidak terlihat tetapi dapat dipahami seperti keberadaan udara. Begitu juga ketika seseorang didekati hendaknya ia diperlakukan dengan kebaikan dan kehormatan sehingga ia merasa ramah dan senang menanggapi sang da'i secara positif. ${ }^{3}$

Metodologi Dakwah Nabi telah menjadi topik yang sangat penting yang dibahas dari waktu ke waktu oleh banyak cendekiawan Muslim di Indonesia bentuk langsung atau tidak langsung. Muhammad al-Ghazali berpendapat bahwa pemilihan metodologi yang tepat digunakan dalam Dakwah Islam, yang sejalan dengan Al-Qur'an dan As-Sunnah memiliki pengaruh yang besar terhadap kebangkitan manusia terhadap cara berpikirnya yang diikuti oleh kebangkitan diri mereka. Dakwah Islam tentu akan mencapai tujuannya jika pola pikir atau pandangan orang tentang kebenaran telah dikoreksi. Perlindungan Dien (agama) adalah tujuan tertinggi dari Maqasid al-Syariah, diikuti oleh perlindungan kehidupan, perlindungan keturunan, perlindungan akal dan perlindungan kekayaan dan harta benda. Al-Qur'an dan Sunnah Nabi telah membahas banyak hal cara dan metode yang dimaksudkan untuk semua waktu dan ruang tentang bagaimana melindungi agama Islam. Dakwah disyariatkan baik oleh Islam sumber sebagai salah satu cara yang paling penting tentang perlindungan Dien al-Islam (Islam dan ajarannya). Itu yang terbaik cara yang digunakan oleh semua Nabi Allah dan pengikut mereka. ${ }^{4}$

Majelis Taklim sebagai lembaga pendidikan Islam nonformal yang memiliki peran penting dalam proses sosialisasi dan akulturasi dalam kehidupan masyarakat yang pada nantinya akan membawa sebuah kemaslahatan. Majelis Taklim merupakan wadah untuk menambah ilmu agama dan mengembangkan

3 Maulana Akbar Shah Tun Aung, Da'wah Through Acreative Approach, 2016, https://www.researchgate.net/publication/316595639_Islamic_da'wah_through_a_creative_ideol ogical_approach.

${ }^{4}$ Fatmir Shehu, "Methodology of Prophetic, Journal of Education and Social Sciences 6 (2017): 9-17, https://doi.org/ISSN 2289-1552. 
kehidupan beragama. ${ }^{5}$ Adapun majelis taklim yang dipimpin oleh Ustadz Wildan dan Kyai Halimatus di Desa Suci-Panti-Jember, ini merupakan majelis taklim sifatnya rutianan yang dilaksanakan setiap Senin malam Selasa. Dalam penyampaian dakwahnya menggunakan metode dan strategi yang telah dicontohkan oleh Nabi Muhammad SAW, sehingga semua pesan dakwah yang disampaikannya mudah diterima oleh masyarakat. Maka dari itu, hal tersebut akan berimplikasi terhadap religiusitas masyarakat akan ajaran agama Islam. Oleh karena itu, dalam riset ini akan menggali lebih komprehensif terkait; 1) bagaimana peran majelis taklim dalam meningkatkan religiusitas masyarakat dan bagaimana antusiasisme masyarakat dalam majelis taklim, 2). kitab-kitab apa saja yang dijadikan rujukan dalam penyampain dakwahnya.

\section{Metode Penelitian}

Dalam menyusun hasil temuan, penelitian ini dikategorikan dalam penelitian jenis penelitian deskriptif- kualitatif. Jenis ini digunakan untuk menjabarkan terkait seluruh bahan yang terdapat dalam proses penelitian baik dari observation, interview, documentation. Sifat inti dari penelitian kualitatif adalah bahwa penelitian itu meneliti cara orang memahami pengalaman nyata dan konkret mereka sendiri dalam pikiran mereka sendiri dan dengan kata-kata mereka sendiri. Ketika ditanya tentang bagaimana mereka memahami beberapa aspek kehidupan mereka, orang biasanya menjawab dalam bahasa sehari-hari menggunakan konsep sehari-hari. Data yang dihasilkan disebut sebagai "narasi". Penelitian kualitatif menyerang masalah secara berbeda dari cara penelitian kuantitatif. Hal ini didasarkan pada gagasan mendasar bahwa "kenyataan" adalah subjektif: Setiap manusia membangun individu, pandangan pribadi dunia atas dasar nya spesifik dan, setidaknya sampai batas tertentu, interaksi orangspesifik dengan dunia luar. (termasuk orang-orang yang merupakan bagian dari dunia ini). Akibatnya, banyak dari apa yang orang, termasuk peneliti, anggap sebagai kenyataan sebenarnya terdiri dari serangkaian kesan, kesimpulan, dan pendapat dalam pikiran setiap orang. ${ }^{6}$ Dalam proses pengumpulan data, penulis menggunakan pertama observasi, wawancara, dan dokumentasi, sehingga diharapkan memperoleh data-data yang komprehensif. Narasumber dalam penelitian ini yakni Ustadz dan Kyai yang melaksanakan kegiatan Majelis Taklim, dalam proses analisis data penulis mengacu pada tiga skema yang ditawarkan oleh Miles and Hubermans yakni; pengumpulan data, penyajian

5 Ahmad Marzuki, Mohamad Zaidin Mohamad, and Rohaizan Baru, Role of Majelis Taklim and Adaptation Muslim Minority with Tengger Local Culture, International Journal of Academic Research in Business and Social Sciences 8, no. 10 (2018), https://doi.org/10.6007/ijarbss/v8-i10/4730.

${ }^{6}$ Arthur Cropley, Qualitative Research Methods: A Practice-Oriented Introduction for Students of Psychology and Education. (Jerman: University of Hamburg, 2021),5-6 https://doi.org/doi: 10.13140/RG.2.1.3095.6888. 
data, reduksi data, hingga penarikan kesimpulan. Dalam keabsahan data, penulis menggunakan teknik triangulasi. ${ }^{7}$

Gambar 1.Skema ketika melakukan analisis data data Miles dan Huberman.

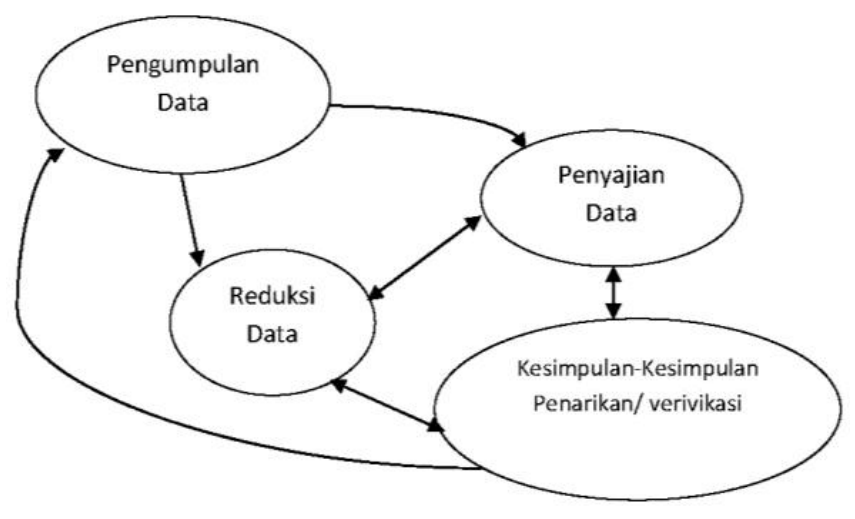

\section{Hasil dan Pembahasan}

\section{Peran Majelis Taklim dalam Meningkatkan Religiusitas Masyarakat dan Antusiasisme Masyarakat dalam Majelis Taklim}

Dari hasil interview dan survey dilapangan penulis akan mendeskripsikan bahwa dalam melaksanakan kegiatan dakwah Ustadz Wildan mengoptimalisasikan latar yang sangat efektif yang biasa kita sebut dengan Majelis Taklim. Sehingga ketika penyampaian dakwahnya bisa dikunjungi dengan mudah dan nyaman oleh masyarakat, dimana majelis taklim ini dilaksanakan di Mushola Al-ikhlas Desa Suci Kec. Panti Kab. Jember. Majelis taklim yang terdapat di Desa Suci ini biasanya dilaksanakan setiap Senin malam Selasa, yang dipimpin oleh Ustadz Wildan, yang memiliki tujuan agar dapat memberikan tambahan ilmu agama bagi masyarakat. Dimana sudah kita ketahui bahwa kegiatan dalam berdakwah memiliki nilai positif bagi manusia, karena pada hakikatnya bertujuan terkait hal "menyeru dalam hal kebajikan, mencegah pada yang munkar".

Istilah dakwah digunakan dalam Al-Qur`an dengan beberapa konteks, antara lain: mereka adalah "menyeru orang ke jalan Allah." Apalagi kata dakwah cukup komprehensif yaitu menyempurnakan ibadah kita sendiri dan pelayanan kepada Tuhan, alasan kita diciptakan di dunia ini, dan itu sejalan dengan Islam sebagai dīnee (agama), cara hidup. Dakwah adalah salah satu amalan yang paling mulia yang mengandung pahala yang tinggi, sebagai AlQur'an telah mengatakan, "Ajaklah (manusia, ya Muhammad) ke jalanmu Tuhan (yaitu Islam) dengan kebijaksanaan (yaitu dengan Wahyu Ilahi dan AlQur`an) dan dakwah yang adil, dan berdebatlah dengan mereka dengan cara yang lebih baik. Sesungguhnya Tuhanmu lebih mengetahui siapa yang sesat dari

${ }^{7}$ Sugiono, Metode Penelitian Kuantitatif-Kualitatif Dan R\&D (Bandung: Alfabeta, 2014), 274 . 
jalan-Nya, dan Dialah yang paling mengetahui orang-orang yang mendapat petunjuk." Ayat ini juga menandakan metode penting dalam berdakwah dalam Islam. Sayyid Qutb menunjukkan bahwa ayat tersebut menunjukkan Nabi diperintahkan untuk melanjutkan upaya, menyerukan orang untuk mengikuti iman ilahi, melalui kebijaksanaan dan nasihat yang baik, dan menyampaikan argumennya dengan cara yang ramah. Di dalam kasus penentang Nabi yang menyerang dan bertindak agresif, Qutb menambahkan bahwa "hukuman harus dari jenis yang sama dengan agresi, atau Nabi dapat memilih cara pengampunan yang lebih baik dan kesabaran dalam kesulitan, meski mampu menuntut hukuman. Dakwah adalah salah satu sarana untuk menyebarkan Islam kepada orang lain. ${ }^{8}$ Dakwah dalam Islam memiliki peran yang membedakan dalam membangun nilai-nilai dan prinsip-prinsip dalam masyarakat, dan yang paling penting dari nilai-nilai ini adalah keamanan, dalam arti yang komprehensif, diperlukan baik bagi individu maupun masyarakat. ${ }^{9}$

Majelis taklim merupakan lembaga pendidikan informal bagi umat Islam untuk mendalami ajaran Islam. Dalam pembentukan majelis taklim berakar pada gerakan dakwah Nabi yang menciptakan sebuah forum diskusi agama dengan para sahabat di Masjid. Kesadaran akan pentingnya belajar mengacu pada hadits Nabi Muhammad SAW yang mengatakan "belajar itu wajib Karena kewajiban tersebut masyarakat kemudian mendirikan kelompok masyarakat di masjid, lingkungan dan tempat lainnya yaitu Majelis taklim. ${ }^{10}$ Keberadaan majelis taklim di masyarakat menjadi sangat penting. Ini karena majelis taklim memiliki kedudukan dan peran strategis, dalam menyampaikan nilai-nilai dakwah di masyarakat lebih khusus untuk ibu-ibu terkait agama dan ilmu pengetahuan. Selain itu, majelis menjadi sarana komunikasi dan sarana untuk mempererat persaudaraan antar sesama muslim. Selain itu, majelis taklim dapat berfungsi sebagai media dalam pengembangan mental keislaman masyarakat dalam menghadapi era informasi saat ini globalisasi. Oleh karena itu dapat digunakan sebagai media pencerahan dan pemberdayaan masyarakat. Dengan kata lain, keberadaan majelis taklim secara umum dapat dimanfaatkan oleh semua kalangan masyarakat sebagai lembaga pendidikan nonformal. ${ }^{11}$ Sehingga

${ }^{8}$ Abdul Salam Muhamad Shukri, "An Overview of the Concept, Meanings, Nature and Significance of Islamic Da'wah," JOURNAL OF ISLAMIC SCIENCES AND COMPARATIVE STUDIES: AL-ITQĀN 5, no. 1 (2021).

${ }^{9}$ Mostafa Hassan Mohamed Al-Khaiat, Mohammed Muneerdeen Olodo Al-Shafi'i, Mohamed Fathy Mohamed Abdelgelil, Nur Sakiinah Binti Ab Aziz, THE PRINCIPLES OF ISLAMIC DA'WAH AND ITS ROLE IN ACHIEVING SECURITY, MALAYSIAN JOURNAL FOR ISLAMIC STUDIES 3, no. 1 (2019).

${ }^{10}$ Wiwi Siti Sajaroh and Sarah Hajar Mahmudah, NU Women's Role in Narrating Moderate Islam with Majelis Taklim, Advances in Social Science, Education and Humanities Research (ASSEHR) 129, no. Icsps 2017 (2018): 37275, https://doi.org/10.2991/icsps17.2018.80.

11 Mujahidin, Urgensi Majelis Taklim Sebagai Lembaga Dakwah Di Masyarakat, Alhadharah: Jurnal Ilmu Dakwah 17, no. 33 (2019): 1, https://doi.org/10.18592/alhadharah.v17i33.2372. 
masyarakat sangat antusias dalam mengikuti majelis taklim yang dilaksanakan oleh Ustadz Wildan, karena dalam penyampaian petuahnya dengan lemah lembut dan bahasa yang digunakan mudah dipahami masyarakat setempat.

Salah satu fakta penting tentang pendidikan adalah dengan mendidik diri sendiri yaitu membebaskan pikirannya dari prasangka dan kebodohan tentang daerah lain, budaya, dan agama. Pendidikan akan membuka pikiran seseorang terhadap informasi dan pengetahuan baru. Dengan mengambil beberapa waktu untuk belajar tentang agama umat Islam, siapa pun akan datang untuk melihat Islam yang indah. Kata "Islam" adalah kata Arab yang artinya "penyerahan" atau "penyerahan" kehendak seseorang kepada satu-satunya Tuhan yang benar, dikenal dalam bahasa Arab sebagai "Allah". Orang yang menyerahkan kehendaknya kepada Tuhan adalah disebut dalam bahasa Arab sebagai "Muslim". Kata ini berasal dari kata yang sama akarnya sebagai kata Arab "salam", yang berarti "damai". Dengan demikian, agama Islam mengajarkan bahwa untuk mencapai perdamaian sejati pikiran dan keteguhan hati, seseorang harus tunduk kepada Allah dan hidup menurut Hukum Ilahi-Nya yang diwahyukan. Kebenaran yang paling penting yang diwahyukan Allah kepada manusia adalah bahwa tidak ada sesuatu pun yang ilahi atau berhak disembah kecuali Allah SWT, demikianlah manusia harus tunduk kepada-Nya. Kata "Muslim" berarti orang yang tunduk pada kehendak Allah, terlepas dari ras, kebangsaan atau latar belakang etnis mereka. Menjadi seorang Muslim memerlukan penyerahan yang disengaja dan ketaatan aktif kepada Allah, dan hidup sesuai dengan pesan-Nya.

Kehidupan umat Islam di tingkat individu dan masyarakat diatur oleh seperangkat aturan yang berbeda. Set pertama adalah fondasi yang menggambarkan hubungan antara manusia dan Sang Pencipta, Allah. Ini berkaitan dengan semua masalah keyakinan seorang Muslim. Ini adalah kumpulan inti yang setiap lainnya berlabuh padanya. Himpunan tersebut dikenal sebagai 'Aqidah (keyakinan). Dasar dari iman Islam adalah keyakinan pada Keesaan Tuhan Yang Maha Esa, Allah, Tuhan Ibrahim (Abraham), Nuh (Nuh), Musa (Musa) dan Isa (Yesus). Islam mengajarkan bahwa kepercayaan murni pada Satu Tuhan adalah intuitif dalam diri manusia dan dengan demikian memenuhi kecenderungan alami jiwa. Aturan kedua adalah Syariah (Hukum) terdiri dari aturan konstitutif dan regulatif yang berhubungan dengan transformasi dan mewujudkan iman dan keyakinan ke dalam tindakan dan praktik sehari-hari karena seperangkat aturan ini berasal dari sumber utama: AlQur'an dan As-Sunnah. Semua Muslim harus menjalankan urusan mereka sesuai dengan aturan-aturan tersebut. Perangkat aturan ini terdiri dari dua komponen yang dikenal sebagai Ibadah (berurusan dengan praktik ritual dengan Sang Pencipta, Allah) berkaitan dengan kepraktisan cara untuk melakukan ritus dan ritual, untuk memahami, dan menjelaskan hubungan dengan Allah SWT. Komponen lainnya adalah Mu amalah (berurusan dengan dunia dan makhluk hidup transaksi). Syariah menjadi praktis aspek inilah yang memberikan jawaban atas setiap aspek manusia kehidupan yang menggambarkan kepraktisan 
kehidupan sehari-hari dengan mendefinisikan aturan yang mengatur kegiatan sosial, politik, dan ekonomi. Ini Komponen mu`amalah mendefinisikan pelaksanaan kegiatan ekonomi dalam sistem ekonomi Islam dan menetapkan aturan untuk bisnis, komersial, keuangan, dan sistem perbankan. Bagian ketiga adalah Akhlaq (perilaku moral pribadi, watak) kepedulian terhadap perilaku, sikap, dan etos kerja di mana seorang Muslim harus hidup dalam masyarakat. Sebagai hasil dari mengikuti panduan tentang 'Aqidah dan Syariah, seorang Muslim akan bertindak menurut ajaran islam maka akhlaq adalah transformasi 'Aqidah dan Syariah dalam individu seorang Muslim. ${ }^{12}$

Islam sebagai dien al-haq adalah Islam yang diciptakan oleh Sang Pencipta yang haq sehingga manusia sebagai ciptaan-Nya harus menyerahkan diri kepada Sang Pencipta dan mengamalkan Islam dalam kehidupannya, baik sebagai individu, keluarga, masyarakat atau negara dan antarnegara. Pengenalan yang jelas seperti ini adalah sesuatu yang dapat mengantarkan manusia kepada hidayah Allah. Dengan demikian Islam sebagai al-dien sejati adalah sebuah petunjuk yang lurus untuk membawa manusia kepada keridhaan Allah SWT sedangkan selain Islam adalah jahiliyah yang akan membawa kepada kesesatan dan kemurkaan-Nya. Islam mengandung makna kepasrahan dan penyerahan total kepada Allah SWT dan segala aturan-Nya yang diturunkan kepada Nabi pilihan-Nya, Muhammad (SAW). Islam adalah agama fitrah, karena Islam adalah sesuatu yang melekat pada diri manusia dan dibawa sejak lahir melalui fitrah ciptaan Allah, artinya manusia sejak awal memiliki naluri keagamaan tauhid. Islam sesuai dengan ciri-cirinya, seperti bangunan yang sempurna dengan landasan iman yang kokoh dan sendi-sendi tiang berupa peribadatan kepada Allah SWT dan diperindah dengan akhlak yang mulia. Sedangkan regulasi dalam syari'at berfungsi untuk memperkuat bangunan. Sedangkan dakwah dan jihad yang benar adalah pagar yang menjaga dari kerusakan yang dilakukan oleh musuh-musuh Islam. Islam memperhatikan keseimbangan duniawi dan ukhrawi. Islam menggambarkan keutuhan dan kesatuan dalam segala aspek, seperti memperhatikan perdamaian, optimisme dalam mencapai kebahagiaan hidup, menata kehidupan pribadi, keluarga, masyarakat, negara dan dunia secara keseluruhan. Aturan semua ciptaan Allah SWT di alam ini untuk kembali kepada hukum-Nya. Islam adalah agama yang abadi Allah SWT yang diturunkan kepada Nabi Muhammad SAW. Semua ajaran surgawi sebelumnya adalah kesatuan dari ajaran ketuhanan dalam berbagai bentuk yang terus diperbarui sesuai dengan perkembangan zaman, dunia, manusia, dan tuntutan dakwah saat ini. Ciri-ciri Islam adalah ciri-ciri khusus yang dimiliki oleh Islam dan tidak dimiliki oleh agama-agama lain. Adapun ciri khas Islam didasarkan pada sejumlah ayat Al-Qur'an, bukan dari yang lain. Sifat ini dimiliki oleh Islam karena bersumber dari ayat-ayat Al-Qur'an, ajarannya antara lain: bersumber dari Allah SWT; kemanusiaan dan universal; lengkap dan menyeluruh; mudah

12 Mohd Fuad Salleh, "ISLAM THE SYSTEM OF LIFE," no. November (2015), https://doi.org/10.13140/RG.2.1.1403.0801. 
dan sederhana; fleksibel; adil; seimbang; melengkapi; asli dan abadi, dan mengundang pemikiran yang objektif dan rasional. ${ }^{13}$

Kaitannya dengan religiusitas dalam setiap diri individu tentunya akan berbeda, karena setiap individu memiliki motif tersendiri dalam menjalankan perintah agama. Religiusitas sebagai preferensi individu, emosi, keyakinan, dan tindakan yang merujuk pada agama yang ada (atau buatan sendiri). 'Agama' kemudian menunjukkan keseluruhan sistem simbol budaya yang menanggapi masalah makna dan kontingensi dengan menyinggung suatu realitas transenden yang mempengaruhi kehidupan sehari-hari tetapitidak dapat dikontrol secara langsung. Sistem simbol agama menggabungkan mitos, elemen etika dan ritual serta barang keselamatan. ${ }^{14}$ Religiusitas mengacu pada keyakinan dan praktik ritualistic agama, baik dengan menghadiri tempat keagamaan atau dengan berdoa. Religiusitas dapat menawarkan pedoman untuk perilaku manusia, bertujuan untuk mengurangi tren yang merusak diri sendiri, mencegah adopsi dari perilaku yang buruk. ${ }^{15}$

Sedangkan kata Islam secara harafiah berarti ketundukan kepada segala sesuatu yang memiliki kekuasaan atas orang tersebut, dalam Islam, itu secara khusus mengacu pada ketaatan kepada Allah SWT. Berdasarkan seseorang dapat tunduk kepada Tuhan dalam tiga tingkatan. Pada tingkat pertama, islam, ini dilakukan melalui karya atau agama praktek-praktek seperti ibadah dan ritual (misalnya, kinerja shalat, puasa, sedekah (zakat), haji, dan kewajiban sosial lainnya. Tingkat iman melibatkan pemahaman dan keyakinan kepada Tuhan, para nabi-Nya, malaikat, kitab suci, dan kebangkitan. Tingkat akhir, ihsan, berbeda dengan tingkatan sebelumnya, adalah bati dimensi di mana seseorang melakukan tindakan supererogatory ibadah dalam pengabdiannya kepada Allah SWT. Ini bisa dilihat sebagai transformasi spiritual dari eksoteris ke esoterik dengan tujuan menjadi insan kamil (manusia sempurna atau universal) atau aktualisasi kebajikan dan kebaikan, sesuai dengan peran yang telah Allah tetapkan untuk manusia. Ihsan, oleh karena itu, adalah tingkat tertinggi yang dapat dicapai oleh seseorang, dan dengan mencapainya, seorang Muslim diasumsikan telah benar-benar tunduk. Di lain kata-kata, penyerahan total atau ketaatan hanya mungkin jika seseorang mengetahui fakta keberadaannya dan memiliki pendirian yang teguh iman berdasarkan pengetahuan dan keyakinan. Dengan latar belakang ini, dapat dikatakan bahwa definisi agama dan, dengan perluasan, religiusitas, menekankan pada tindakan tubuh atau aktivitas manusia (Islam), pikiran atau pemahaman tentang Tuhan (iman), dan roh atau aktualisasi

13 Baharuddin Husin, Supriyatin, Zaimudin, Imron Zabidi, The Meaning And Characteristics Of Islam In The Qur'an, International Journal of Psychosocial Rehabilitation 24, no. 1 (2020), https://doi.org/ISSN: 14757192.

14 Jörg Stolz, Explaining Religiosity: Towards a Unified Theoretical Model, British Journal of Sociology 60, no. 2 (2009): 34576, https://doi.org/10.1111/j.1468-4446.2009.01234.x.

${ }^{15}$ Sonia Regina Zerbetto et al., Religiosity and Spirituality: Mechanisms of Positive Influence on the Life and Treatment of Alcoholics, Escola Anna Nery - Revista de Enfermagem 21, no. 1 (2017): 18, https://doi.org/10.5935/1414-8145.20170005.

Siti Humairoh | 191 
keutamaan dan kebaikan (ihsan). Pada dasar dari kerangka ini, konstruk religiusitas untuk skala yang dikembangkan dalam penelitian ini diukur dengan item menilai berbagai aspek keislaman seseorang, iman, dan ihsan. Dari perspektif Islam, agama adalah ikatan antara Tuhan sebagai Realitas Tertinggi dan ciptaan-Nya, dengan manusia sebagai salah satu ciptaan. Ini adalah cara hidup (al-din) atau jalan (tariqat) dengan Tuhan sebagai jangkar yang mencakup jumlah total pekerjaan seorang Muslim. Dalam Islam, sumber yang paling berharga itu memberikan gambaran yang komprehensif tentang al-din yang terkandung dalam sebuah hadits yang dikenal dengan "Hadīth Jibril". Hadits ini penting karena menggambarkan al-din sebagai konsep dengan tiga konstituen penting. Yang pertama adalah Islam, yang meliputi kewajiban agama seseorang ditandai dengan tindakan ibadah; yang kedua adalah iman, yang mewakili kognitif dan sistem kepercayaan dalam memahami Tuhan; dan ketiga, ihsan, yang merepresentasikan aktualisasi keunggulan moral dan spiritual. Ketiga konsep ini tidak terpisah tetapi terhubung dan diperlukan untuk masing-masing lain untuk menjadi pribadi yang seimbang dan religius. Pandangan ini tersirat dalam tulisan-tulisan masa lalu Cendekiawan dan peneliti muslim seperti AlQardhawi yang menganggap hubungan yang erat antara ketiga konsep tersebut. ${ }^{16}$

\section{Beberapa Kitab-Kitab yang Menjadi Rujukan/ Dikaji dalam Majelis Taklim}

Dakwah dalam pengertian terbatas yang sama dengan ceramah adalah kegiatan mengajak masyarakat untuk memahami, menghayati dan mengamalkan Islam dan mencegah orang melakukan itu adalah dilarang oleh Allah SWT. Kedua kegiatan tersebut adalah dirangkum dalam istilah amar ma'ruf nahi munkar. Dalam arti luas dipahami sebagai upaya untuk merekonstruksi masyarakat sesuai dengan syariat Islam cita-cita, yang merupakan rahmat bagi alam semesta. Menjadi menyadari itu harus dilakukan dalam bentuk dakwah bil lisan, bil kitabah dan bil hal. Dakwah bil lisan dapat dilakukan melalui tatap muka komunikasi, seperti kuliah atau mendengar dan belajar di majelis agama, atau menggunakan media elektronik seperti seperti radio dan televisi. Dakwah bil katabah atau melalui tulisan menyampaikan pesan-pesan keagamaan melalui media cetak seperti buletin, brosur, koran, majalah dan buku. Sedangkan dakwah bil hal adalah dakwah dengan keteladanan dan aksi sosial. Islam adalah agama pesan atau agama dakwah. Hal ini sesuai dengan kewajiban Nabi Muhammad SAW. Yaitu untuk menyampaikan wahyu yang diterimanya kepada umat manusia. Padahal, dakwah adalah penghubung hubungan antara wahyu yang datang dari Allah SWT dengan manusia yang petunjuk, hidayahnya dan jalan hidup yang harus dilalui. Lebih jauh lagi, berdakwah adalah perjalanan

${ }^{16}$ Nor Diana Mohd Mahudin et al., Religiosity among Muslims: A Scale Development and Validation Study, Makara Human Behavior Studies in Asia 20, no. 2 (2016): 109, https://doi.org/10.7454/mssh.v20i2.3492. 
hidup para nabi yang kemudian diteruskan oleh para sahabat dan Muslim hingga saat ini. ${ }^{17}$

Dari hasil interview dilapangan menunjukkan bahwa dalam melakukan kegiatan, terutama kegiatan dalam berdakwah tentunya harus mempunyai dasar atau landasan dalam menyampaikan pesan dakwahnya. Seperti yang sudah kita ketahui bahwa dalam Islam rujukan yang paling sering digunakan adalah AlQur'an dan Hadits. Begitupun dengan kegiatan dakwah dalam majelis taklim di Desa Suci Kec. Panti ini telah menggunakan beberapa kitab yang akan dijadikan rujukan atau yang dikaji, diantaranya yaitu;

\section{Kitab aqidatul awam}

Adapun dari hasil wawancara bahwa kitab aqidatul awam merupakan kitab yang mengkaji tentang ilmu tauhid (iman, aqidah). Dimana kitab ini menjadi salah satu kitab yang wajib dikaji baik itu di lembaga- lembaga pendidikan Islam, seperti pondok pesantren yang terdapat di Indonesia, maupun dalam majelis taklim di masyarakat. Oleh karena itu salah satu kitab yang dikaji dalam majelis taklim ini yaitu kitab aqidatul awam, dan hukum mempelajarinya adalah fardhu 'ain yakni wajib bagi setiap orang mukallaf untuk mengetahui bagaimana aqidah yang benar. Aqidah Islam seperti yang diajarkan oleh generasi awal umat Islam dan oleh para ulama besar yang menunjukkan kesalehan dan pemahaman mereka yang benar tentang Islam diperlukan secara agama dan sesuatu untuk ditiru bagi seorang Muslim yang taat. Aqidah, dalam Islam, oleh karena itu merupakan ideologi dan praktik karena menjauhkan seseorang dari kemusyrikan. Tujuan utama dari Aqidah Islam adalah untuk membuat seseorang percaya dan mengakui keberadaan dan keesaan Allah Yang Maha Tinggi. Berdasarkan perkembangan tersebut, maka wajib bagi setiap muslim untuk mengetahui akidah Islam yang benar, memahaminya dengan baik dan kemudian meyakininya sesuai dengan pemahaman dan keyakinan para sahabat Nabi (RA). Bahkan, jika ini dilakukan dengan benar, seseorang akan bebas dari perbudakan selain Allah sehingga menerima dan mengikuti hukum ilahi yang dibawa oleh Nabi Muhammad (SAW).

Aqidah Islam menempati posisi yang menonjol dalam Islam. Posisi ini membuatnya menggantikan semua praktik bhakti lainnya. Dengan demikian, esensi Aqidah Islam diturunkan kepada semua Nabi dan Rasul Allah dan ditahbiskan kepada seluruh umat manusia dan Jin untuk menerima dan mengikuti ajarannya dan mengamalkannya sesuai dengan ilustrasi yang ditunjukkan oleh Nabi Allah. Oleh karena itu, umurnya setua generasi pertama umat manusia. Hal ini mengingat fakta bahwa Adam (AS) turun ke bumi dan dari keturunannya Allah SWT melahirkan sebuah bangsa yang percaya Tauhid murni dan mengikuti agama Islam yang benar tetapi kemudian mereka menyimpang dari jalan tauhid. Akar dari Aqidah Islam yakni menunjukkan iman

17 Abdullah, Mohammad Hatta, Muaz Tanjung, Mukhtaruddin, Rahmah Fithriani, Thoughts and Da'wah Activities of Female Islamic Preachers in Medan, Indonesia, International Conference on Multidisciplinary Research, no. Icmr 2018 (2020): 27783, https://doi.org/10.5220/0008883902770283. 
yang teguh dan tak tergoyahkan yang tidak akan pernah terbuka untuk keraguan apa pun oleh yang melihatnya. Yaitu dengan cara beriman kepada Allah dan apa yang menjadi hak-Nya ibadah dan ketaatan, Malaikat-Nya, Kitab Suci, Nabi/Rasul, Hari Akhir serta takdir Allah -Al-Qada. Dalam Hadits Jibril (AS ), Nabi menjelaskan rukun Aqidah (iman) yang harus diimani oleh setiap Muslim, ketika ditanya, "Apa itu iman?", dan dia menjawab, "Beriman kepada Allah, para malaikat-Nya. , Kitab-kitab-Nya, Rasul-rasul-Nya, Hari Akhir dan takdir kebaikan dan kejahatan. Kita harus menyimpulkan, pada saat ini, bahwa wajib bagi setiap Muslim untuk mengetahui rukun-rukun ini dan mempelajarinya dengan pemahaman yang benar dan meyakininya. Seseorang tidak akan dianggap sebagai seorang Muslim yang bonafid hanya dengan mengetahui dan memahami pilar-pilar ini sampai ia mencapai tingkat di mana ia tunduk dan menerapkan apa yang dijelaskan, dalam Hadits Jibril sebagai Iman. ${ }^{18}$

Dalam pendidikan Islam itu harus bisa membentuk seseorang menjadi individu yang memiliki pengetahuan mendalam tentang pendekatan Islam sehingga Islam menjadi kekuatan pembimbingnya. Kesadaran akan prinsipprinsip Islam adalah dasar untuk memahami ajaran Islam dan dasar ilmu dalam Islam adalah aqidah karena itu adalah kekuatan yang mencegah seseorang dari melakukan dosa. Aqidah yang benar bisa hanya dapat diperoleh melalui kombinasi ilmu, dalil naqli dan logika. Dalam pembentukan pribadi muslim yang sejati harus dimulai dengan pengembangan aqidah karena akidah yang kuat akan membuka jalan bagi akhlak yang tinggi yang akan diwujudkan melalui kognitif, afektif dan psikomotorik. Belajar dan pemahaman aqidah sangat penting dalam membentuk mukmin kamil, yaitu kesempurnaan beriman. sementara itu menyatakan bahwa upaya berkelanjutan dalam membangun aqidah dalam masyarakat Muslim dapat melindungi serangan dari orang-orang kafir dan keraguan dari mereka yang tersesat. Masyarakat yang memiliki iman atau akidah sebagai pedomannya akan mampu mewujudkan perbuatan baik dan kemudian berdampak positif bagi individu dan masyarakat lainnya. Pendeknya, pengetahuan tentang aqidah dan kemampuan untuk memahaminya dapat menciptakan manusia yang luar biasa, mewujudkan potensi sejati mereka seperti yang ditentukan oleh Islam. ${ }^{19}$

\section{Kitab mabadi'ul fiqhiyah}

Kitab mabadiul fiqhiyah merupakan salah satu dari beberapa kitab populer di kalangan masyarakat baik itu di lembaga pendidikan formal maupun non formal. Dimana kitab ini menjelaskan tentang ilmu hukum dalam islam serta terdapat tanya jawab seputar fiqih syafi'iyah yang dimulai dari penjelasan

${ }^{18}$ Attahir Shehu Mainiyo, The Role of Islamic Aqidah and Its Impact on the Lives of Muslims

2015,https://www.researchgate.net/publication/307477684_The_Role_of_Islamic_Aqidah_and_ its_Impact_on_the_lives_of_Contemporary_Muslims.

${ }_{19}$ Ahmad Munawar Ismail, Aqidah as a Basis of Social Tolerance: The Malaysian Experience, International Journal of Islamic Thought 1, no. 1 (2012): 17, https://doi.org/10.24035/ijit.01.2012.001. 
hukum dalam islam. Adapun kitab ini dapat dikategorikan sebagai landasan dasar bagi masyarakat dalam mempelajari ilmu fiqih. Fiqh secara harfiah berarti 'pemahaman' atau 'pengetahuan'. Biasa disebut 'yurisprudensi Islam' dalam bahasa Inggris, fiqh adalah pemahaman manusia tentang Syariah dan prosesnya dimana ahli hukum Muslim (fuqaha) mengekstraksi keputusan hokum (ahkam) dari sumber suci Islam: Al-Qur'an dan Sunnah (perkataan dan amalan Nabi). Fiqh tidak hanya mengacu pada aturan hukum ini tetapi juga kumpulan yurisprudensi hokum teks-teks yang dihasilkan oleh para ahli hukum Islam. Fiqh adalah proses manusia dalam mencari pemahaman syariah. Seperti yang lain sistem yurisprudensi, fiqh adalah manusiawi, temporal dan lokal. Fiqh (yurisprudensi Islam) adalah bagian dari hukum Islam yang mengandung Ahkam Syari'ah Amaliyah, ketentuan-ketentuan dan hukum-hukum yang menjadi pedoman persoalan-persoalan praktis (amaliyah) tentang bagaimana beribadah kepada Allah (Allah SWT), untuk melakukan hubungan manusia sehari-hari dalam untuk memenuhi kebutuhan hidup, untuk melakukan hubungan dalam keluarga dan untuk memerintah kehidupan masyarakat untuk menjamin perdamaian dalam hubungan masyarakat. Karena fiqh mendominasi pedoman praktis sehari-hari manusia, maka ini disiplin ilmu sering disebut hukum Islam. Secara non formal dan formal lembaga pendidikan seperti pondok pesantren, pesantren,sekolah (madrasah) dan sekolah umum,bahkan dalam kajian di kalangan masyarakat seperti halnya majelis taklim yang dilaksanakan di Desa Suci ini. Oleh karena itu, fiqh harus dipelajari dan dipahami sehingga kita sebagai umat Islam dapat mengetahui dengan benar dari segala hokum dalam Islam. ${ }^{20}$

Fiqh Islam adalah baik sistem agama dan hukum, yang membuatnya mendekati sinonim dengan syariah, arti dari yang ditunjukkan dalam Quran (42:13), (5:48) dan (45:18). Di sana Allah menyatakan diri-Nya (yang pertama dan saja) Legislator, Yang mengungkapkan syariat termasuk agama serta sistem hukum. Oleh karena itu wajar bahwa fiqh harus berurusan dengan ibadah agama bersama dengan transaksi. Itu juga wajar jika masalah transaksi harus dikaitkan dengan agama baik dari segi sumber, tafsir, tafsir, dan lain-lain jalan pemikiran, penyelidikan dan deduksi. Dengan kata lain, itu mencakup, dalam arti luas, semua aspek agama, kehidupan politik dan sipil di samping undang-undang lain yang mengatur ritual dan ibadah agama (ibadah seperti sholat, puasa, haji, zakat, dll) terkait dengan kinerja dan pantangan. Ini mencakup seluruh bidang hukum keluarga, hokum waris dan akad yang memberikan segala persoalan yang timbul dalam kehidupan bermasyarakat (mu'amalat). Ini juga termasuk hukum pidana dan tata cara dan akhirnya hukum tata negara dan administrasi dan pengaturan negara dan pelaksanaan perang dan semua aspek kehidupan publik dan pribadi dan bisnis. Semua harus diakui dan diatur oleh Islam fiqh. Arti penting fiqh begitu besar sehingga merupakan studi tentang hak dan kewajiban seseorang

${ }^{20}$ M. Athoillah, The Methods of Teaching and Learning Fiqh in Islamic Boarding School, Islamic School and Public School, Jurnal Pendidikan Islam 2, no. 1 (2016): 127, https://doi.org/10.15575/jpi.v2i1.697. 
yang berasal dari Al-Qur'an, sunnah Nabi, ijma' atau ijma' dan nalar analogis atau qiyas serta sumber-sumber perundang-undangan lainnya dalam yurisprudensi Islam. Perlindungan hak dan kewajiban individu terhadap masyarakat adalah tujuan dari pengetahuan hukum ini. Dimana didalamnya terletak landasan keadilan, ketertiban, dan kesejahteraan umat manusia. Manusia terikat oleh tanggung jawab dan tugas terhadap Penciptanya dan terhadap sesama makhluk. Pengetahuannya tentang fiqh membuatnya sadar akan kewajiban tersebut dan cara umat manusia dapat melepaskannya dan melalui pengetahuan seperti itu mereka dapat mengevaluasi validitas atau sebaliknya dari tindakan/kinerjanya. ${ }^{21}$

\section{Kitab lubabul hadits}

Kegiatan dakwah dalam majelis taklim yang dipimpin oleh Ustadz Wildan ini juga mengkaji tentang kitab lubabul hadits. Kitab lubabul hadits adalah kitab yang berisi tentang hadis-hadis pilihan yang dikarang oleh Jalaludin bin Kamaludin as suyuthi hadis hadis tersebut berisi tentang Fadilah- Fadilah atau keutamaan-keutamaan dalam Islam. Kitab ini berisi tentang 40 bab dan disetiap bab berisi 10 Hadits. Diantara bab yang diajarkan dalam kajian setiap Senin malam Selasa yaitu keutamaan ilmu dan orang yang berilmu keutamaan lafadz lailahaillallah dan keutamaan bismillah serta keutamaan shalawat kepada nabi Muhammad shallallahu alaihi wasallam. Pengkajian kitab lubabul hadits ini dikaji setiap malam Senin malam Selasa yang ditujukan untuk santrisantri mushola TPQ dan masyarakat melalui pengeras suara sehingga masyarakat bisa mendengarkan dan ikut mengkaji tentang keutamaankeutamaan dalam beramal seperti keutamaan dalam berilmu dan menghormati ulama atau Kyai atau Ustad. Dan juga dijelaskan tentang keutamaan-keutamaan dalam Islam seperti keutamaan lafadz lailahaillallah, keutamaan basmalah, keutamaan sholawat, keutamaan wudhu, keutamaan shalat dan keutamaankeutamaan yang lain. Pengajian kitab lubabul hadits ini ditujukan utamanya agar menjadi pendorong dan penyemangat kepada masyarakat agar mereka lebih semangat lagi dalam beramal dan mengerjakan syariat Islam dan juga agar mereka menambah wawasan ilmu pengetahuan khususnya dalam agama agar mereka tidak hanya taklid atau ikut-ikutan dalam menjalankan perintah Allah.

Salah satu contoh penjelasan tentang keutamaan dalam bersedekah/praktik filantropi Islam. Salah satu tema utama dalam Al-Qur'an dan Sunnah adalah kasih sayang terhadap yang rentan dan keadilan sosial bagi individu yang kurang beruntung dalam masyarakat. Misalnya, Al-Qur'an mengajarkan umat Islam bahwa, "(mereka) tidak akan mencapai kebenaran sampai [mereka] menafkahkan hal-hal yang (mereka) sukai.". Ajaran-ajaran ini mendorong umat Islam untuk mempraktikkan sedekah, seringkali sejak usia

${ }^{21}$ Anas P Aboobacker, Fiqh: Definition, Scope, Subject Matter, And Characteristic Features, n.d., https://www.academia.edu/3526996/FIQH_DEFINITION_SCOPE_SUBJECT_MATTER_AND _CHARACTERISTIC_FEATURES\#: :text=Asshafiee defines fiqh as the,of a process of reasoning. 
sangat muda, dan menanamkan keyakinan kepada mereka bahwa mereka akan dibalas dengan jumlah yang jauh lebih besar di akhirat. Dengan demikian, filantropi adalah salah satu penyewa sentral dalam Islam yang mengilhami umat Islam untuk terikat satu sama lain dan dengan komunitas mereka yang lebih besar sebagai bentuk ibadah dan untuk manfaat yang lebih besar dari kesemuanya. Al-Qur'an mengatakan: "Tetapi orang benar adalah orang yang memberikan kekayaan, karena cinta kepada-Nya kepada kerabat dan anak yatim dan orang miskin dan orang yang dalam perjalanan dan kepada orang-orang yang meminta, dan untuk membebaskan budak". Sedekah sering kali melampaui kontribusi keuangan untuk memasukkan tindakan memberi karena belas kasih atau kemurahan hati yang dilakukan untuk memberi manfaat bagi orang lain. Nabi bersabda: Setiap perbuatan baik adalah sedekah; dan Ada shadaqah bagi setiap Muslim. Jika dia tidak bisa memberi karena dia tidak punya uang, biarkan dia bekerja sehingga dia bisa menghidupi dirinya sendiri dan bersedekah; jika dia tidak dapat bekerja, maka biarkan dia membantu seseorang yang membutuhkan bantuannya; jika dia tidak bisa melakukan itu, biarkan dia menyatukan kebaikan; jika dia tidak bisa melakukan itu, maka dia tidak boleh melakukan kejahatan atau menyakiti orang lain. Filantropi, dengan kata sederhana, berarti tindakan yang dilakukan untuk kesejahteraan umat manusia. Setiap agama memiliki komponen filantropi; namun, Islam mengambil langkah lebih jauh dengan membuat beberapa bentuk wajib. Islam sangat menekankan pada mendukung orang miskin. Tema menyeluruh untuk 'tindakan amal' dalam Islam berakar pada dua prinsip dasar: mengembangkan kasih sayang untuk orang lain dan menunjukkan kebaikan terhadap satu sama lain. ${ }^{22}$

\section{Penutup}

Misi kegiatan dakwah pada intinya merupakan suatu kegiatan atau proses yang dilakukan dengan kesadaran dan berencana untuk mengajak manusia ke jalan Allah, untuk memperbaiki situasi menjadi lebih baik (dakwah adalah promosi dan pengembangan) dalam rangka mencapai tujuan tertentu, yaitu untuk hidup bahagia di dunia akhirat. Dengan demikian beberapa definisi dan terminologi dakwah yang baik menurut arti etimologis, semua menunjuk ke kegiatan yang bertujuan positif pada manusia. Perubahan positif diwujudkan dengan peningkatan keimanan. jika definisi dakwah dikaitkan dengan beberapa fenomena dakwah, maka dapat dinyatakan bahwa dakwah adalah proses peningkatan iman dalam diri manusia menurut syariat Islam bahwa proses menunjukkan aktivitas yang terus menerus, terus menerus dan bertahap. Seperti peningkatan kualitas perubahan positif: dari buruk menjadi baik, atau dari baik menjadi lebih baik. Seperti halnya kegiatan majelis taklim yang merupakan suatu wadah bagi masyarakat dalam rangka untuk memperoleh ilmu tentang keislaman, yang sifatnya lebih terbuka dan biasanya dilakukan secara rutinan.

${ }^{22}$ Mohamed Amersi and Ayatollah Seyed Fazel Milani, Philanthropy and Islam, Philanthropy Impact (England and Wales, May 2019), https://www.philanthropyimpact.org/article/philanthropy-and-islam. 
Oleh karena itu, dalam penyampaian dakwahnya juga harus disesuaikan dengan kondisi lokal masyarakat, yang tujuannya agar mudah dipahami dan diterima oleh masyarakat itu sendiri.Dari pemaparan fokus penelitian diatas maka penulis akan mendeskripsikan hasil penelitiannya yakni sebagai berikut; (1) Peran Majelis taklim khususnya di masyarakat Suci- Panti sangat berperan penting bagi masyarakat itu sendiri seperti dari segi religiusitasnya yang pada dasarnya tercermin dalam pengamalan aqidah, syariah, dan akhlak (iman, islam, dan ihsan). Dalam majelis taklim yang diselenggarakan setiap senin malam selasa ini mendapat respon yang sangat baik dari masyarakat bahkan masyarakat sangat antusias ketika kajian berlangsung, selain itu dalam majelis tersebut diadakan sesi diskusi atau tanya jawab yang tujuannya agar masyarakat lebih memahami terkait pesan dakwah yang disampaikan oleh Ustadz Wildan. (2). Adapun kitab yang dijadikan rujukan dalam majelis taklim yang dipimpin oleh Ustadz Wildan yaitu terdiri dari; aqidatul awam, mabadi'ul fiqhiyah, dan lubabul hadits, yang dikupas secara mendalam. Dimana masing-masing kitab tersebut akan menjelaskan terkait bagaiamana menjadi insan yang baik dan bertqwa kepada Allah SWT. Serta kegiatan majelis taklim ini ditujukan utamanya agar menjadi pendorong dan penyemangat kepada masyarakat agar mereka lebih semangat lagi dalam beramal dan mengerjakan syariat Islam dan juga agar mereka menambah wawasan ilmu pengetahuan khususnya dalam agama agar mereka tidak hanya taklid atau ikut-ikutan dalam menjalankan perintah Allah.

Maka dari itu, penulis memiliki keinginan bahwa riset ini dapat menjadi rujukan dan panduan dalam penyusunan bagi peneliti selanjutnya, dengan lebih kritis lagi. Terutama riset yang berkaitan dengan dakwah. Peneliti sangat mengakui bahwa riset yang dilakukan ini belum termasuk dalam kategori kesempurnaan. Maka dari itu, masih banyak peluang untuk peneliti yang lain dalam melaksanakan proses riset dengan tema terkait meninjunya dengan kacamata yang berbeda.

\section{Daftar Pustaka}

Abdullah, Mohammad Hatta, Muaz Tanjung, Mukhtaruddin, Rahmah Fithriani. Thoughts and Da'wah Activities of Female Islamic Preachers in Medan, Indonesia." International Conference on Multidisciplinary Research, no. Icmr 2018 (2020): 27783. https://doi.org/10.5220/0008883902770283.

Aboobacker, Anas P. Fiqh: Definition, Scope, Subject Matter, And Characteristic

Features,https://www.academia.edu/3526996/FIQH_DEFINITION_SCOP E_SUBJECT_MATTER_AND_CHARACTERISTIC_FEATURES\#: :text $=$ Asshafiee defines fiqh as the,of a process of reasoning.

Amersi, Mohamed, and Ayatollah Seyed Fazel Milani. Philanthropy and Islam. Philanthropy Impact. England and Wales, May 2019. https://www.philanthropy-impact.org/article/philanthropy-and-islam.

Athoillah, M. The Methods of Teaching and Learning Fiqh in Islamic Boarding 
School, Islamic School and Public School. Jurnal Pendidikan Islam 2, no. 1 (2016): 127. https://doi.org/10.15575/jpi.v2i1.697.

Baharuddin Husin, Supriyatin, Zaimudin, Imron Zabidi. The Meaning And

Characteristics Of Islam In The Qur'an. International Journal of Psychosocial Rehabilitation 24, no. 1 (2020). https://doi.org/ISSN: 1475 7192.

Cropley, Arthur. Qualitative Research Methods: A Practice-Oriented Introduction for Students of Psychology and Education. Jerman: University of Hamburg, 2021. https://doi.org/doi: 10.13140/RG.2.1.3095.6888.

Hauser, Albrecht. Da'Wah: Islamic Mission and Its Current Implications."

International Bulletin of Missionary Research 36 No.4, no. October (2012): 189-94.

Ismail, Ahmad Munawar. "Aqidah as a Basis of Social Tolerance: The Malaysian Experience." International Journal of Islamic Thought 1, no. 1 (2012): 1-7. https://doi.org/10.24035/ijit.01.2012.001.

Mahudin, Nor Diana Mohd, Noraini Mohd Noor, Mariam Adawiah Dzulkifli, and Nazariah Sharie Janon. Religiosity among Muslims: A Scale Development and Validation Study Makara Human Behavior Studies in Asia 20, no. 2 (2016): 109. https://doi.org/10.7454/mssh.v20i2.3492.

Mainiyo, Attahir Shehu. The Role of Islamic Aqidah and Its Impact on the Lives of Muslims Abstract:," 2015, 1-15. https://www.researchgate.net/publication/307477684_The_Role_of_Islami c_Aqidah_and_its_Impact_on_the_lives_of_Contemporary_Muslims.

Marzuki, Ahmad, Mohamad Zaidin Mohamad, and Rohaizan Baru. "Role of Majelis Taklim and Adaptation Muslim Minority with Tengger Local Culture." International Journal of Academic Research in Business and Social Sciences 8, no. 10 (2018). https://doi.org/10.6007/ijarbss/v8i10/4730.

Maulana Akbar Shah $\quad$ Tun $\quad$ Aung. DAWAHTHROUGHACREATIVEAPPROACH,"

2016.https://www.researchgate.net/publication/316595639_Islamic_da'wah _through_a_creative_ideological_approach.

Mostafa Hassan Mohamed Al-Khaiat, Mohammed Muneerdeen Olodo AlShafii, Mohamed Fathy Mohamed Abdelgelil, Nur Sakiinah Binti Ab Aziz. THE PRINCIPLES OF ISLAMIC DA'WAH AND IT'S ROLE IN ACHIEVING SECURITY. MALAYSIAN JOURNAL FOR ISLAMIC STUDIES 3, no. 1 (2019).

Mubasyaroh, Mubasyaroh. Develop Quality People Through Da'Wah in the Face of the Asean Economic Community (Aec). Addin 10, no. 2 (2016): 449. https://doi.org/10.21043/addin.v10i2.1785.

Mujahidin, Mujahidin. Urgensi Majelis Taklim Sebagai Lembaga Dakwah Di Masyarakat. Alhadharah: Jurnal Ilmu Dakwah 17, no. 33 (2019): 1. https://doi.org/10.18592/alhadharah.v17i33.2372.

Sajaroh, Wiwi Siti, and Sarah Hajar Mahmudah. NU Womens Role in Narrating 
Moderate Islam with Majelis Taklim. Advances in Social Science, Education and Humanities Research (ASSEHR) 129, no. Icsps 2017 (2018): 372-75. https://doi.org/10.2991/icsps-17.2018.80.

Salleh, Mohd Fuad. ISLAM THE SYSTEM OF LIFE, no. November (2015). https://doi.org/10.13140/RG.2.1.1403.0801.

Shehu, Fatmir. Methodology of Prophetic. Journal of Education and Social Sciences 6 (2017): 917. https://doi.org/ISSN 2289-1552.

Shukri, Abdul Salam Muhamad. An Overview of the Concept, Meanings, Nature and Significance of Islamic Da wah." JOURNAL OF ISLAMIC SCIENCES AND COMPARATIVE STUDIES: AL-ITQĀN 5, no. 1 (2021).

Stolz, Jörg. "Explaining Religiosity: Towards a Unified Theoretical Model." British Journal of Sociology 60, no. 2 (2009): 345-76. https://doi.org/10.1111/j.1468-4446.2009.01234.x.

Sugiono. Metode Penelitian Kuantitatif-Kualitatif Dan R\&D. Bandung: Alfabeta, 2014.

Zerbetto, Sonia Regina, Angélica Martins de Souza Gonçalves, Nátaly Santile, Sueli Aparecida Frari Galera, Ana Carolina Acorinte, and Gisele Giovannetti. Religiosity and Spirituality: Mechanisms of Positive Influence on the Life and Treatment of Alcoholics. Escola Anna Nery - Revista de Enfermagem 21, no. 1 (2017): 18. https://doi.org/10.5935/14148145.20170005. 